\title{
Ultrasonographic Evidence of Predominance of Acute Extracapsular and Chronic Intrasynovial Patterns in 100 Cases of Psoriatic Hand Dactylitis
}

\author{
Nicolò Girolimetto, Pierluigi Macchioni, Ilaria Tinazzi, Luisa Costa ${ }^{\circledR}$, Dennis McGonagle, \\ Rosario Peluso, Antonio Del Puente, Olga Addimanda, Antonio Marchetta, Niccolò Possemato, \\ Marco Tasso, Carlo Salvarani, Raffaele Scarpa ${ }^{\circledR}$, and Francesco Caso
}

\begin{abstract}
Objective. To use ultrasonography to study whether the duration of psoriatic dactylitis was associated with different patterns of extracapsular and synovial-based involvement.

Methods. One hundred cases of hand dactylitis from 85 patients with psoriatic arthritis (PsA) were consecutively enrolled in a multicenter cross-sectional study and divided into 2 groups according to dactylitis duration (shorter or longer than the median: 20 weeks). All dactylitis fingers were investigated using high-frequency ultrasound both in greyscale (GS) and power Doppler (PD), evaluating the presence of flexor tenosynovitis, soft tissue edema, subcutaneous PD signal (PDS), extensor tendon involvement, and joint synovitis.

Results. Cases with a shorter dactylitis duration ( $<20$ weeks) had a significantly higher prevalence of GS flexor tenosynovitis of grade $>2$, PD flexor tenosynovitis, soft tissue edema, and subcutaneous PDS ( $p=0.001, p<0.001, p<0.05$, and $p=0.001$, respectively). However, the presence of synovitis in GS and PD mode (in both cases at proximal interphalangeal level) was more frequent in patients with longer dactylitis duration $(\mathrm{p}<0.001)$. When detected in the chronic form, flexor tenosynovitis was grade 2 or lower.

Conclusion. In a large cohort of PsA hand dactylitis, we found a predominant extracapsular inflammation (flexor tenosynovitis and soft tissue edema) in early cases and a high prevalence of joint synovitis at proximal interphalangeal level in the chronic form. However, longitudinal imaging studies are needed to clarify these aspects. (First Release November 1 2019; J Rheumatol 2020;47:227-33; doi:10.3899/jrheum.190046)
\end{abstract}

Key Indexing Terms:

DACTYLITIS

TENOSYNOVITIS

ULTRASOUND

EDEMA

\section{PSORIATIC ARTHRITIS FLEXOR TENDON}

\footnotetext{
From the Department of Clinical Medicine and Surgery, Rheumatology Research Unit, University Federico II, Naples; Department of Rheumatology, Azienda USL-Institute for Research and Health Care (IRCCS) di Reggio Emilia, Reggio Emilia; Unit of Rheumatology, Ospedale Sacro Cuore, Negrar, Verona, Italy; UK National Institute for Health Research (NIHR) Leeds Musculoskeletal Biomedical Research Centre, Leeds Teaching Hospitals Trust and the University of Leeds, UK; Rheumatology Unit, University of Modena and Reggio Emilia, Reggio Emilia, Italy.

N. Girolimetto, MD, Department of Clinical Medicine and Surgery, Rheumatology Research Unit, University Federico II; P. Macchioni, MD, Department of Rheumatology, Azienda USL-IRCCS di Reggio Emilia; I. Tinazzi, MD, Unit of Rheumatology, Ospedale Sacro Cuore; L. Costa, MD, PhD, Assistant Professor, Department of Clinical Medicine and Surgery, Rheumatology Research Unit, University Federico II; D. McGonagle, MD, PhD, Professor, FRCPI, NIHR Leeds Musculoskeletal Biomedical Research Centre, Leeds Teaching Hospitals Trust and the University of Leeds; R. Peluso, MD, PhD, Assistant Professor, Department of Clinical Medicine and Surgery, Rheumatology Research Unit, University Federico II; A. Del Puente, MD, Assistant Professor, Department of Clinical Medicine and Surgery, Rheumatology Research Unit, University Federico II; O. Addimanda, MD, Department of Rheumatology, Azienda USL-IRCCS di Reggio Emilia; A. Marchetta, MD, Unit of Rheumatology, Ospedale Sacro Cuore; N. Possemato, MD, Department of Rheumatology, Azienda USL-IRCCS di Reggio Emilia; M. Tasso, MD, Department of Clinical Medicine and Surgery,

Rheumatology Research Unit, University Federico II; C. Salvarani, MD,
}

Full Professor, Department of Rheumatology, Azienda USL-IRCCS di Reggio Emilia, and Rheumatology Unit, University of Modena and Reggio Emilia; R. Scarpa, MD, Full Professor, Department of Clinical Medicine and Surgery, Rheumatology Research Unit, University Federico II; F. Caso, MD, PhD, Assistant Professor, Department of Clinical Medicine and Surgery, Rheumatology Research Unit, University Federico II.

Address correspondence to Dr. R. Scarpa, Rheumatology Unit, Department of Clinical Medicine and Surgery, University Federico II, Via S.Pansini 5,80131 Naples, Italy.E-mail:rscarpa@unina.it

Accepted for publication April 24, 2019.

Dactylitis is a common feature of psoriatic arthritis (PsA), occurring in $16 \%$ to $49 \%$ of patients with PsA, mostly in early disease ${ }^{1,2,3}$. As the most specific PsA manifestation it has been included in the ClASsification for Psoriatic ARthritis (CASPAR) criteria $^{4,5}$, although it has been observed in all forms of spondyloarthritis ${ }^{6}$, including the enteropathic form ${ }^{7}$. Dactylitis is defined as diffuse and uniform swelling of the entire digit and it is considered a clinical marker of disease severity ${ }^{8,9}$. Clinically, it can present as a tender, painful, warm, and erythematous digit (acute form). It can also present as a swollen paucisymptomatic

Personal non-commercial use only. The Journal of Rheumatology Copyright (c) 2020. All rights reserved. 
digit, not associated with inflammatory modifications (chronic form $)^{10}$, which remains poorly understood ${ }^{11,12}$.

Dactylitis was long considered to be the result of the association of the metacarpophalangeal (MCP), proximal interphalangeal (PIP), and distal interphalangeal (DIP) joints with flexor tenosynovitis ${ }^{13,14}$. In the 1990s, early ultrasound (US) studies reported a predominant flexor tenosynovitis, while the frequency of coexisting joint synovitis varied from $16 \%$ to $62 \% 15,16,17$, and these data were confirmed by subsequent magnetic resonance imaging (MRI) studies ${ }^{18,19,20}$. These results led the authors to conclude that flexor tenosynovitis was a major contributor to the clinical appearance of dactylitis, and joint synovitis was a variable coexisting feature. Fournié, et $a l^{21}$ used US to show diffuse digital soft tissue inflammation in dactylitic patients (reported as subcutaneous and extratendinous) and termed this lesion pseudotenosynovitis. A recent study independently reported that this lesion was useful in the differentiation of PsA from rheumatoid arthritis ${ }^{22}$.

Only a recent US study of 48 cases of PsA dactylitis evaluated the correlation between sonographic features and duration of dactylitis. That study highlighted a significantly higher prevalence of flexor tenosynovitis and peritendinous soft tissue edema in acute form $(<24$ weeks $)$ and joint synovitis in the chronic form ( $>24$ weeks $)^{23}$. We tested the hypothesis that earlier disease may be associated with a greater degree of extracapsular pathology, in line with prominent accessory pulley involvement in early disease. This multicenter observational cross-sectional study was designed to confirm in a greater number of patients the association between US patterns of disease compartmentalization in dactylitis and its duration.

\section{MATERIALS AND METHODS}

Patients. We performed a cross-sectional multicenter study on consecutively enrolled PsA patients with finger dactylitis who were in 3 Italian rheumatology centers (Naples, Reggio Emilia, and Negrar) with a recognized expertise in PsA and US imaging, between August 2017 and September 2018. The study was approved by the local ethics committees of the participating centers and was conducted in conformity with The Declaration of Helsinki (Ethical committee approval number: 5/12). Written informed consent was obtained from all participants.

The inclusion criteria were the fulfillment of CASPAR criteria in patients older than 18 years $^{1}$ having an acute or chronic dactylitis ${ }^{2}$ with a duration of more than a month. The exclusion criteria were the following: (1) current engagement in heavy manual work, (2) recent history of hand trauma, (3) treatment with biologic synthetic disease-modifying antirheumatic drugs (DMARD), and (4) a previous corticosteroid injection in the involved finger.

Before US examination, a clinical assessment was performed by clinicians (AM, CS, RS) with longstanding expertise in the field of PsA who diagnosed the dactylitis using the dactylometer and the Leeds Dactylitis Index $(\mathrm{LDI})^{24}$. The LDI measures the ratio of the circumference of the involved digit to the circumference of the contralateral digit; a minimum difference of $10 \%$ is necessary to define a dactylitic digit. The ratio of circumference is multiplied by a tenderness score $(0=$ no tenderness, $1=$ tender, 2 = tender and winces, $3=$ tender and withdraws).

The rheumatologic evaluation included tenderness of the involved finger, tender joint count (TJC), and swollen joint count (SJC). Erythrocyte sedimentation rate (ESR), C-reactive protein (CRP), and rheumatoid factor were collected. The duration of dactylitis was defined from the onset of reported diffuse digital swelling and pain.

For the purposes of analysis, we divided all cases of dactylitis into 2 groups according to its duration (shorter or longer than the median: 20 weeks). Moreover, all the cases were split into quartiles based on dactylitis duration.

US protocol. US examination of the dactylitis finger was performed by 3 rheumatologists (NG, PM, IT), expert in musculoskeletal US examination and blinded to clinical and laboratory data. All US scans were performed using a MyLab 70XVG machine equipped with a 6-18 MHz linear transducer (Esaote SpA). The US greyscale (GS) imaging measurements were optimized for maximal image resolution. Power Doppler (PD) settings were standardized at the following values: $500 \mathrm{~Hz}$ for pulse repetition frequency, 3 for wall filter, 4 for persistence, and color gain 45-55\%. The window of the color box was restricted to the areas studied.

Flexor and extensor tendons, MCP, PIP, and DIP joints of the affected fingers were assessed by GS and PD US evaluation in longitudinal and transverse scanning views, in accordance with current guidelines and publications ${ }^{25,26}$. Joints were examined from both dorsal and volar sides. The following dactylitis-related sonographic lesions were investigated: flexor tenosynovitis (both in GS and in PD mode), soft tissue edema, subcutaneous PD signal (PDS), extensor tendon involvement (including paratenonitis and enthesitis of extensor tendon at proximal-interphalangeal joint), and synovitis (both in GS and in PD mode).

Tenosynovitis was defined in GS according to the Outcome Measures in Rheumatology (OMERACT) definitions ${ }^{27}$. Soft tissue edema was defined as a diffuse hypo/isoechoic thickening of the extratendinous soft tissues around the flexor tendon (pseudotenosynovitis) with positive PDS in the subcutaneous tissue, in long axis view ${ }^{21}$. We defined paratenonitis as a hypoechoic area surrounding a tendon without synovial sheath, with or without peritendinous $\operatorname{PDS}^{28,29}$. Enthesitis of extensor tendon at PIP joint was defined by the presence of hypoechoic and increased thickness of the tendon insertion into the bone, as compared to the body of the tendon and to the contralateral ${ }^{30,31}$.

Synovitis was defined according to the recent European League Against Rheumatism-OMERACT definition as hypoechoic synovial hypertrophy regardless of the presence of effusion and any grade of $\mathrm{PD}$ signal ${ }^{32}$. Tenosynovitis was assessed using the 4-grade semiquantitative scoring scale in GS and Doppler mode, as proposed by the OMERACT US group ${ }^{27}$. Synovitis was scored using a semiquantitative score (0-3) both for GS and Doppler mode, according to studies ${ }^{32,33}$.

Statistical analysis. The statistical analysis was performed using SPSS version 23. All quantitative variables were expressed as mean $\pm \mathrm{SD}$ or median and range in case of strong violation of normality, while qualitative variables were expressed as percentages.

Intraobserver and interobserver reliabilities were obtained in 2 measurements (basal and at 3 months from the first US evaluation) using 20 static images of 20 patients. We used the Cohen's $\kappa$ coefficient for each sonographic lesion, and values $>0.8$ were considered excellent. Continuous variables were compared using $\mathrm{T}$ test or nonparametric tests when appropriate. Noncontinuous variables were compared using chi-square test. Statistical tests were performed at a significance level of $\alpha=0.05$.

\section{RESULTS}

Clinical features of the 2 dactylitis groups. The main demographic, clinical, and laboratory characteristics of the 2 groups (shorter or longer than 20 weeks) are reported in Table 1. Both groups were not significantly different for body mass index, PsA duration, TJC, SJC, ESR, CRP, and therapies. However, patients with longer dactylitis duration were predominantly male $(\mathrm{p}<0.05)$ and older $(\mathrm{p}=0.01)$. The

Personal non-commercial use only. The Journal of Rheumatology Copyright (C) 2020. All rights reserved 
Table 1. Clinical and laboratory features according to dactylitis duration (shorter or longer than the median: 20 weeks).

\begin{tabular}{lccc}
\hline Variables & $<20$ Weeks & $\geq 20$ Weeks & $\mathrm{p}$ \\
\hline Total cases & 54 & 46 & \\
Sex distribution (male/female) & $26 / 28$ & $32 / 14$ & 0.031 \\
Age in yrs, mean \pm SD & $43.7 \pm 15.6$ & $51.4 \pm 13.9$ & 0.01 \\
BMI, kg/m ${ }^{2}$, mean \pm SD) & $25.3 \pm 2.7$ & $26.1 \pm 3.6$ & $\mathrm{~ns}$ \\
PsA duration disease, mos, mean $\pm \mathrm{SD}$ & $45.4 \pm 47.1$ & $52.5 \pm 44.5$ & $\mathrm{~ns}$ \\
Tenderness $(\%)$ & 91 & 42 & $<0.001$ \\
LDI, mean \pm SD & $35.4 \pm 16.2$ & $19.5 \pm 19.5$ & $<0.001$ \\
Patient pain VAS score, mean $\pm \mathrm{SD}$ & $6.8 \pm 2.7$ & $4.9 \pm 2.2$ & $\mathrm{~ns}$ \\
TJC, 68 joints, mean \pm SD & $6.6 \pm 5.1$ & $5.7 \pm 4.1$ & $\mathrm{~ns}$ \\
SJC, 66 joints, mean \pm SD & $3.2 \pm 2.1$ & $2.4 \pm 1.9$ & $\mathrm{~ns}$ \\
ESR, mm/h, mean \pm SD & $19.1 \pm 14.4$ & $17.2 \pm 12.4$ & $\mathrm{~ns}$ \\
CRP, mg/dl, mean \pm SD & $1.1 \pm 1.9$ & $0.8 \pm 1.3$ & $\mathrm{~ns}$ \\
No therapy, $\mathrm{n}(\%)$ & $18(33.3)$ & $18(39.1)$ & $\mathrm{ns}$ \\
Actual therapy with only NSAID, $\mathrm{n}(\%)$ & $4(7.4)$ & $3(6.5)$ & $\mathrm{ns}$ \\
Actual therapy with prednisolone, $\mathrm{n}(\%)$ & $3(5.6)$ & $6(13.1)$ & $\mathrm{ns}$ \\
Actual therapy with csDMARD, $\mathrm{n}(\%)$ & $29(53.7)$ & $19(41.3)$ & $\mathrm{ns}$ \\
Methotrexate, $\mathrm{n}(\%)$ & $16(29.6)$ & $9(19.5)$ & $\mathrm{ns}$ \\
Sulfasalazine, $\mathrm{n}(\%)$ & $9(16.7)$ & $7(15.2)$ & $\mathrm{ns}$ \\
Leflunomide, $\mathrm{n}(\%)$ & $4(7.4)$ & $3(6.5)$ & \\
\hline
\end{tabular}

BMI: body mass index; CRP: C-reactive protein; csDMARD: conventional synthetic disease-modifying antirheumatic drugs; ESR: erythrocyte sedimentation rate; LDI: Leeds Dactylitis Index; NSAID: nonsteroidal antiinflammatory drugs; PsA: psoriatic arthritis; SJC: swollen joint count; TJC: tender joint count; VAS: visual analog scale; ns: not significant.

patients of the 2 groups were significantly different for the frequency of tenderness $(\mathrm{p}<0.001)$. Moreover, the mean values of LDI score and patient pain visual analog scale (VAS) score were significantly higher in cases with shorter dactylitis duration $(\mathrm{p}<0.001)$.

Sonographic intraobserver reliability. For the 3 sonographers (NG, PM, IT), the intraobserver reliability was excellent for all variables $(\kappa>0.8)$. The interobserver reliability depicted by $\kappa$ coefficient was 0.87 (95\% CI $0.81-0.93$ ) for GS flexor tenosynovitis, 0.83 (95\% CI $0.75-0.90$ ) for PD flexor tenosynovitis, 0.89 (95\% CI 0.85-0.93) for soft tissue edema, 0.86 (95\% CI 0.74-0.97) for subcutaneous PDS, 0.88 (95\% CI 0.84-0.92) for extensor tendon involvement, 0.84 (95\% CI 0.76-0.93) for GS synovitis, and 0.91 (95\% CI 0.85-0.96) for PD synovitis.

Sonographic findings. At least 1 US abnormality was found in all patients. Flexor tenosynovitis was seen in $88 \%$ of dactylitis (grade $>2$ in $46 \%$ of cases), while related PD flexor tenosynovitis was observed in $72 \%$ of cases (grade $>2$ in $57 \%$ of cases). Soft tissue edema was present in $91 \%$ of dactylitis and subcutaneous PDS was present in $85 \%$ of cases. Extensor tendon involvement was evident in $12 \%$ of dactylitic fingers (with associated PDS in $10 \%$ of cases). GS synovitis involving at least 1 joint was observed in $40 \%$ of cases; it was present more frequently at PIP level (28\% of cases), while it was present at MCP and DIP level in $15 \%$ and $9 \%$ of cases, respectively. PD synovitis involving at least 1 joint was evident in $21 \%$ of cases; it was more frequently detected at PIP level (17\% of cases) and it was seen at the MCP and DIP levels in 7\% and 4\% of cases, respectively. Simultaneous synovitis of MCP, PIP, and DIP joints was not found in any patient.

Flexor tenosynovitis plus soft tissue edema were present in $79 \%$ of cases, while flexor tenosynovitis plus joint synovitis involving at least 1 joint were observed in $31 \%$ of cases. Soft tissue edema plus joint synovitis involving at least 1 joint were evident in $12 \%$ of dactylitic fingers.

Table 2 shows the frequency of US abnormalities in the 2 groups of patients. Cases with shorter dactylitis duration ( $<20$ weeks) had a significantly higher prevalence of GS flexor tenosynovitis of grade $>2$ and PD flexor tenosynovitis (any grade; $\mathrm{p}=0.001$ and $\mathrm{p}<0.001$, respectively). Extracapsular soft tissue edema was more common in the shorter disease duration group ( $\mathrm{p}<0.05$; Figure 1 and Figure $2)$. Likewise, subcutaneous PDS was more common in the shorter disease duration group $(p=0.001)$. On the other hand, the presence of synovitis in GS and PD mode (in both cases at PIP level) was more frequent in patients with a dactylitis duration $\geq 20$ weeks ( $p<0.001$ and $p=0.02$, respectively). Figure 3 reports the prevalence of selected US abnormalities after splitting cases into quartiles based on dactylitis duration.

We found no differences in the prevalence of the US abnormalities (in particular flexor tenosynovitis, soft tissue edema, and joint synovitis) comparing subjects treated versus not treated with conventional synthetic DMARD either in the general population or in the subgroups with dactylitis duration less than and $>20$ weeks (Table 3 ).

Personal non-commercial use only. The Journal of Rheumatology Copyright (c) 2020. All rights reserved. 
Table 2. Prevalence of ultrasonographic abnormalities according to dactylitis duration (shorter or longer than the median: 20 weeks).

\begin{tabular}{|c|c|c|c|}
\hline Variables & $<20$ Weeks & $\geq 20$ Weeks & $\mathrm{p}$ \\
\hline Total cases & 54 & 46 & \\
\hline GS flexor tenosynovitis, all cases & 93 & 83 & ns \\
\hline GS flexor tenosynovitis grade $\geq 2$ & 65 & 24 & 0.001 \\
\hline PD flexor tenosynovitis, all cases & 87 & 54 & $<0.001$ \\
\hline PD flexor tenosynovitis grade $\geq 2$ & 74 & 37 & 0.001 \\
\hline Soft tissue edema & 97 & 82 & 0.018 \\
\hline PDS & 96 & 71 & 0.001 \\
\hline GS extensor tendon involvement & 9 & 15 & ns \\
\hline PD extensor tendon involvement & 9 & 11 & ns \\
\hline GS synovitis involving at least 1 joint & 18 & 65 & $<0.001$ \\
\hline PD synovitis involving at least 1 joint & 9 & 35 & 0.02 \\
\hline MCP GS synovitis, all cases & 11 & 20 & ns \\
\hline MCP GS synovitis grade $\geq 2$ & 0 & 4 & ns \\
\hline MCP PD synovitis, all cases & 6 & 9 & ns \\
\hline MCP PD synovitis grade $\geq 2$ & 2 & 6 & ns \\
\hline PIP GS synovitis, all cases & 6 & 54 & $<0.001$ \\
\hline PIP GS synovitis grade $\geq 2$ & 6 & 45 & $<0.001$ \\
\hline PIP PD synovitis, all cases & 6 & 30 & 0.001 \\
\hline PIP PD synovitis grade $\geq 2$ & 4 & 4 & ns \\
\hline DIP GS synovitis, all cases & 9 & 8 & ns \\
\hline DIP GS synovitis grade $\geq 2$ & 3 & 6 & ns \\
\hline DIP PD synovitis, all cases & 3 & 4 & ns \\
\hline DIP PD synovitis grade $\geq 2$ & 0 & 0 & ns \\
\hline $\begin{array}{l}\text { GS flexor tenosynovitis plus soft } \\
\text { tissue edema }\end{array}$ & \multicolumn{2}{|c|}{ GS flexor tenosynovitis plus soft } & 0.002 \\
\hline \multicolumn{4}{|c|}{ GS flexor tenosynovitis plus GS synovitis } \\
\hline involving at least 1 joint & 18 & 48 & 0.001 \\
\hline $\begin{array}{l}\text { Soft tissue edema plus GS synovitis } \\
\text { involving at least } 1 \text { joint }\end{array}$ & 19 & 50 & 0.001 \\
\hline
\end{tabular}

Data are percentages. DIP: distal interphalangeal; GS: greyscale; $\mathrm{MCP}$ : metacarpophalangeal; PD: power Doppler; PDS: subcutaneous PD signal; PIP: proximal interphalangeal; ns: not significant.

\section{DISCUSSION}

This is the first multicenter study, to our knowledge, to evaluate the relationship between US lesions and dactylitis duration in a large PsA hand dactylitis cohort using high-frequency US. Our findings revealed that the prevalence of GS flexor tenosynovitis of grade > 2, PD flexor tenosynovitis, soft tissue edema, and subcutaneous PDS are higher in patients with shorter dactylitis duration. Moreover, the mean values of LDI score were significantly higher in cases with shorter dactylitis duration.

On the other hand, the presence of GS synovitis and intraarticular PDS at PIP level was more frequently observed in patients with longer dactylitis duration. However, flexor tenosynovitis was also present in the chronic form but was of a lesser magnitude. These results confirm the association between US patterns of disease compartmentalization in dactylitis and its duration, as already shown in a previous study with a smaller sample of patients ${ }^{23}$.

At present, the natural clinical course of dactylitis remains largely unknown and longitudinal studies on soft tissue changes in dactylitis have never been done. Previous
US $^{15,16,17}$ and MRI ${ }^{18,20,34}$ studies have demonstrated that dactylitis is characterized by the variable association of inflammatory involvement of flexor tendons (tenosynovitis), adjacent soft tissue thickening/edema, and synovitis of MCP, PIP, and DIP joints. The main limits of previous US studies were the very small samples of patients (usually $<30$ dactylitic digits), the low frequency of the probe used ( 7.5 or $10 \mathrm{MHz}$ ), and the absence of PD examination ${ }^{15,16,17}$. In accord with our data, an MRI study by Olivieri, et al of dactylitic toes with a dactylitis duration shorter than 7 weeks showed flexor tenosynovitis and peritendinous soft tissue edema in all patients and a low prevalence of joint synovitis ${ }^{19}$.

In our study, patients were enrolled in a consecutive manner and they were not selected according to treatment. Although we cannot exclude an influence of treatment on presence and severity of US abnormalities, the comparison of the prevalence of any US alterations did not differ between the treated and the untreated patient groups.

Our present study has several limitations. The main one is its cross-sectional nature. The duration of symptoms is therefore obtained only through medical history. Another limitation of our study is the artificial definition of acute or chronic dactylitis based on the median of the duration of symptoms in the patients of our group. In addition, we cannot exclude that patients with dactylitis duration $>20$ weeks could have had a less severe form of dactylitis; only longitudinal studies can clarify these aspects. Moreover, we have used a very general definition of edema because there is currently no agreement on a definition of soft tissue thickening/edema. However, the high intra- and interobserver reliability of US abnormalities supported the validity of this definition. For a more correct evaluation of soft tissue changes in relation to dactylitis duration, it would be useful to use a semiquantitative score. Similarly, there is no precise definition and grading for the subcutaneous PDS. Another possible limitation is that we have enrolled patients with different drug treatments. Currently there are no data about modification induced by treatment of US characteristics of dactylitis. Moreover, no significant differences were present comparing treatment in the 2 groups of patients. Further, we did not evaluate lesions of volar plate, pulley, and extensor tendons at distal phalanx insertion because of limitations of the US machine we used. The study of these structures should be performed with a higher frequency probe $(22-24 \mathrm{MHz})$.

This is the first multicenter study, to our knowledge, that evaluated the relationship between US lesions and dactylitis duration in a large PsA hand dactylitis cohort. Despite limitations of our study, we found a predominance of flexor tenosynovitis, soft tissue edema, and subcutaneous PDS in early cases and a high prevalence of joint synovitis at PIP level in the chronic form. Our findings could suggest a possible change from a predominant extracapsular pattern in the early phase to an intrasynovial pattern in the chronic

Personal non-commercial use only. The Journal of Rheumatology Copyright $\subset$ 2020. All rights reserved 


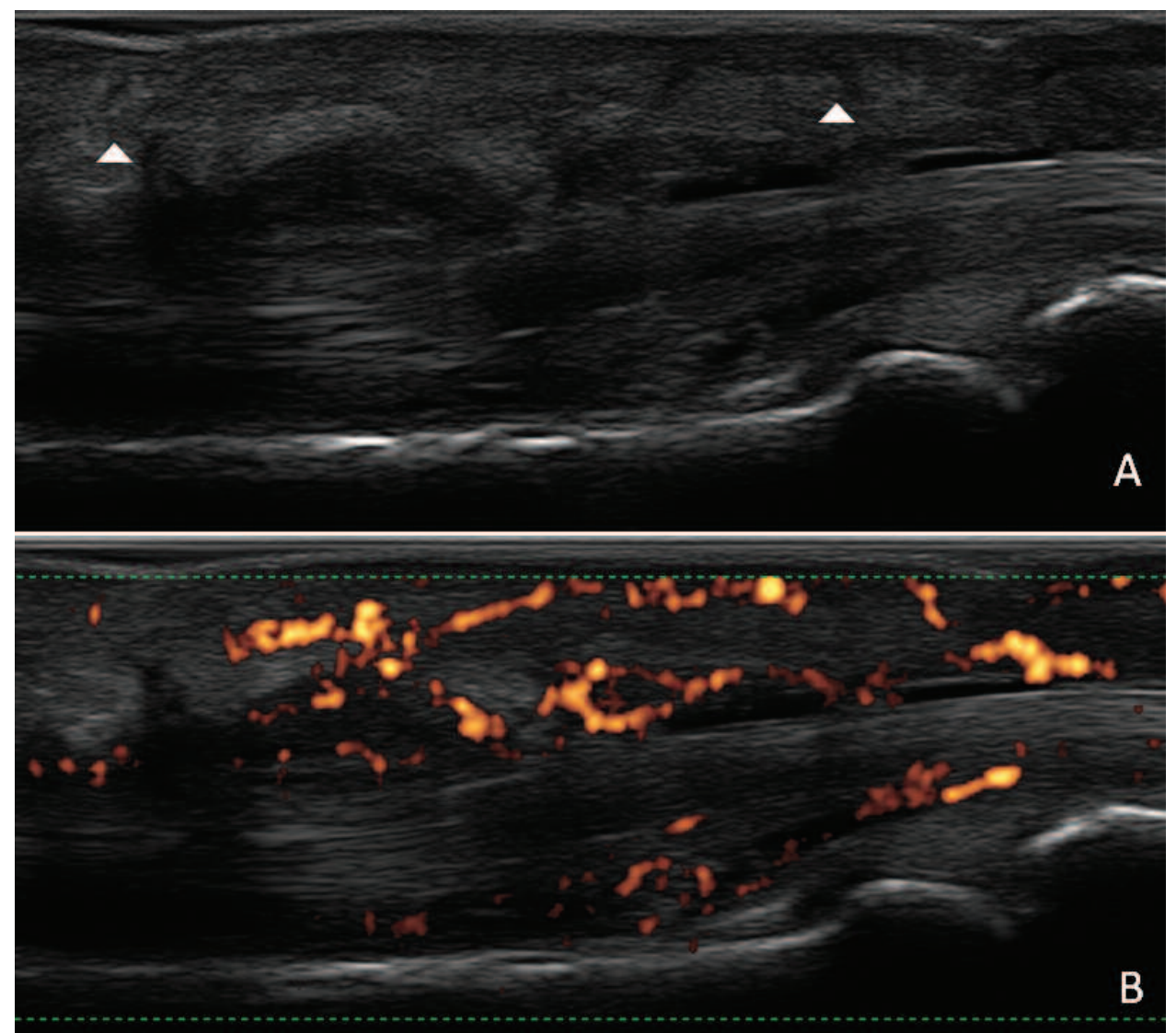

Figure 1. Longitudinal views of dactylitis belonging to the first group (dactylitis duration shorter than 20 weeks). A. Ultrasound shows flexor tenosynovitis of grade 2 with soft tissue edema (white arrowheads), whereas joint synovitis is absent. B. Power Doppler signal (PDS) is present around the tendon fibers and in subdermal tissue; intrarticular PDS is absent.
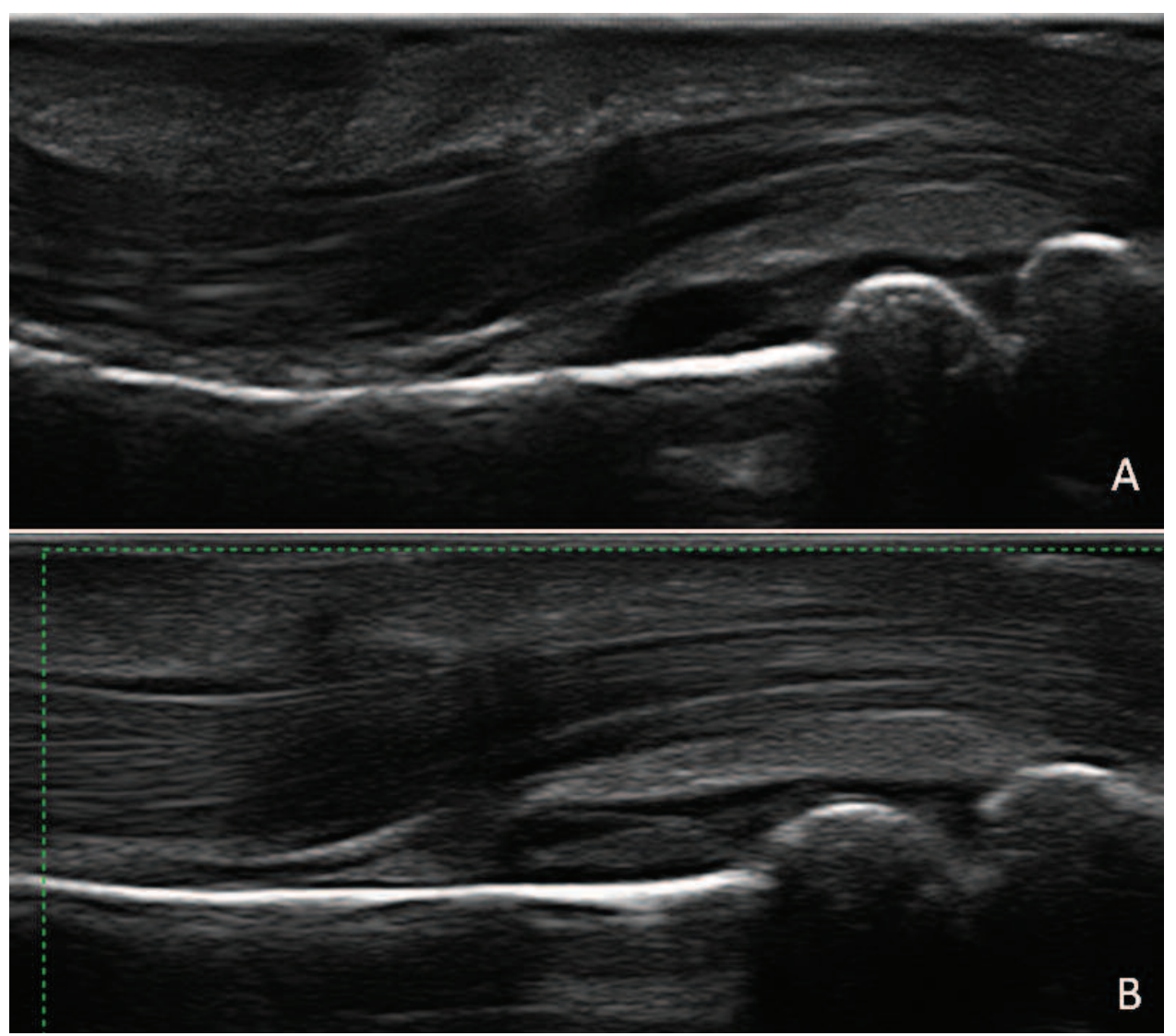

Figure 2. Longitudinal views of dactylitis belonging to the second group (dactylitis duration longer than 20 weeks). A. Ultrasound shows no peritendinous edema, distension of the flexor tendon sheath (grade 1), and of the capsule (grade 3) at proximal interphalangeal joint level. B. Power Doppler signal is absent in the articular, peritendinous, and subcutaneous areas.

\section{Personal non-commercial use only. The Journal of Rheumatology Copyright @ 2020 . All rights reserved.}




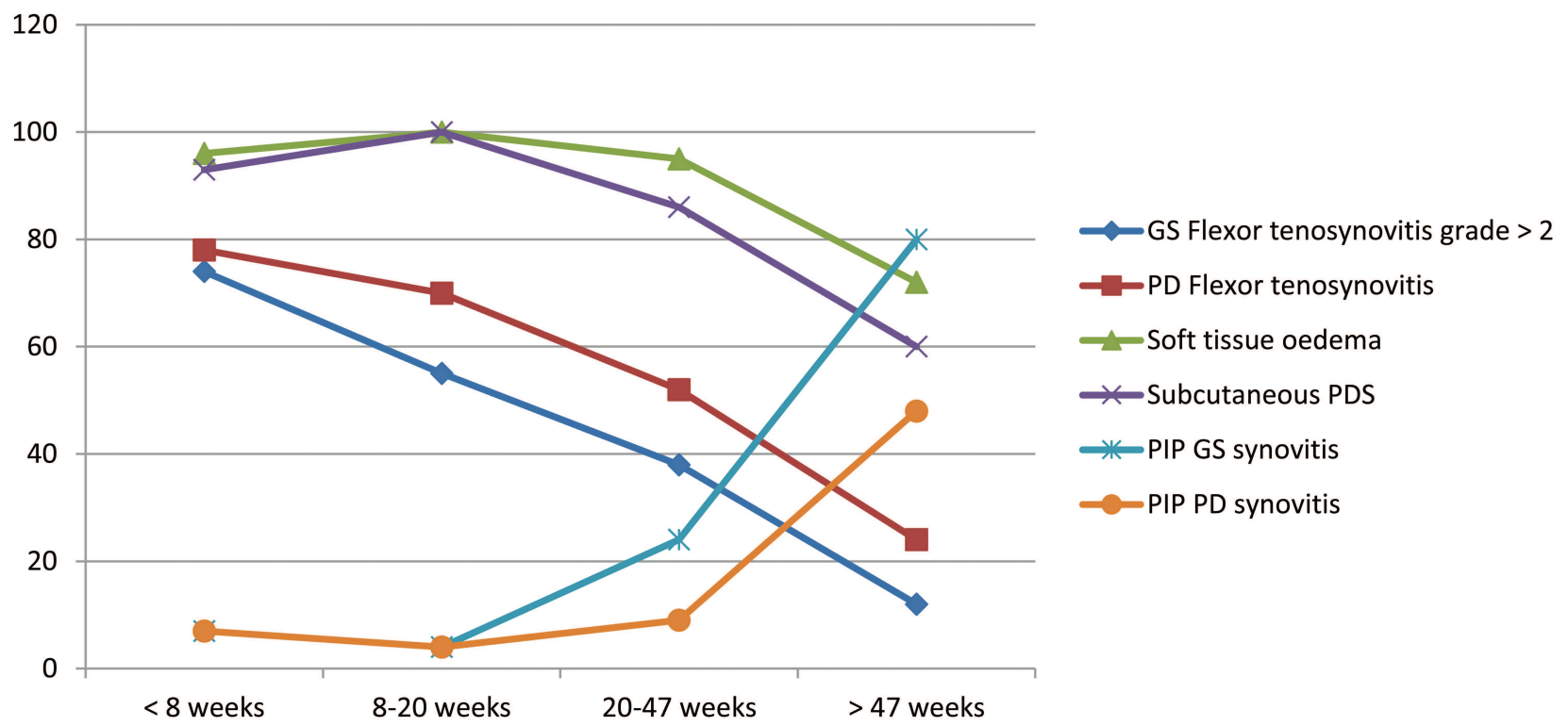

Figure 3. Prevalence of selected US abnormalities after splitting cases into quartiles based on dactylitis duration. US: ultrasound; GS: greyscale; PD: power Doppler; PDS: subcutaneous PD signal; PIP: proximal interphalangeal.

Table 3. Prevalence of ultrasonographic abnormalities according to therapy.

\begin{tabular}{ccc}
\hline Variables & CsDMARD- & CsDMARD- \\
treated & naive \\
Patients & Patients
\end{tabular}

\section{Total cases, $\mathrm{n}$}

GS flexor tenosynovitis

PD flexor tenosynovitis

Soft tissue edema

PDS

GS synovitis involving at least 1 joint

PD synovitis involving at least 1 joint

Cases with dactylitis duration $<20$ weeks, $n$

GS flexor tenosynovitis

PD flexor tenosynovitis

Soft tissue edema

Subcutaneous PDS

GS synovitis involving at least 1 joint

PD synovitis involving at least 1 joint

Cases with dactylitis duration $>20$ weeks, $n$

GS flexor tenosynovitis

PD flexor tenosynovitis

Soft tissue edema

Subcutaneous PDS

GS synovitis involving at least 1 joint

PD synovitis involving at least 1 joint

Data are percentages, except where noted. No $\mathrm{p}$ values were significant. csDMARD: conventional synthetic disease-modifying antirheumatic drugs; GS: greyscale; PD: power Doppler; PDS: subcutaneous PD signal.

evolution. However, longitudinal imaging studies are needed to clarify these aspects.

\section{ACKNOWLEDGMENT}

The authors thank Prof. Stefano Galletti for his suggestions.

\section{REFERENCES}

1. Gladman DD, Ziouzina O, Thavaneswaran A, Chandran V. Dactylitis in psoriatic arthritis: prevalence and response to therapy in the biologic era. J Rheumatol 2013;40:1357-9.

2. Gladman DD, Chandran V. Observational color studies: lessons learnt from the University of Toronto Psoriatic Arthritis Program. Rheumatology 2011;50:25-31.

3. Caso F, Costa L, Atteno M, Del Puente A, Cantarini L, Lubrano E, et al. Simple clinical indicators for early psoriatic arthritis detection. Springerplus 2014;3:759.

4. Taylor W, Gladman D, Helliwell P, Marchesoni A, Mease P, Mielants H; CASPAR Study Group. Classification criteria for psoriatic arthritis: development of new criteria from a large international study. Arthritis Rheum 2006;54:2665-73.

5. Tillett W, Costa L, Jadon D, Wallis D, Cavill C, McHugh J, et al. The ClASsification for Psoriatic ARthritis (CASPAR) criteria - a retrospective feasibility, sensitivity, and specificity study. J Rheumatol 2012;39:154-6.

6. Dougados M, van der Linden S, Juhlin R, Huitfeldt B, Amor B, Calin A, et al. The European Spondylarthropathy Study Group preliminary criteria for the classification of spondylarthropathy. Arthritis Rheum 1991;34:1218-27.

7. Peluso R, Costa L, Caso F, Del Puente A, Di Minno MN, Manguso F, et al. Dactylitis in enteropathic spondyloarthritis. Clin Exp Rheumatol 2016;34:842-7.

8. Olivieri I, Scarano E, Padula A, Giasi V. Dactylitis involving most of the fingers. Clin Exp Rheumatol 2003;21:406.

9. Brockbank JE, Stein M, Schentag CT, Gladman DD. Dactylitis in psoriatic arthritis: a marker for disease severity? Ann Rheum Dis 2005;64:188-90.

10. Gladman DD, Helliwell P, Mease PJ, Nash P, Ritchlin C, Taylor W. Assessment of patients with psoriatic arthritis: a review of currently available measures. Arthritis Rheum 2004;50:24-35.

11. Coates LC, Helliwell PS. Disease measurement-enthesitis, skin, nails, spine and dactylitis. Best Pract Res Clin Rheumatol 2010;24:659-70.

12. Ferguson EG, Coates LC. Optimisation of rheumatology indices: dactylitis and enthesitis in psoriatic arthritis. Clin Exp Rheumatol 2014;32:113-7. 
13. Wright V. Psoriatic arthritis. In: Scott JT, editor. Copeman's textbook of the rheumatic diseases. 5th ed. Edinburgh: Churchill Livingstone; 1978:537-48.

14. Bennett RM. Psoriatic arthritis. In: McCarty DJ, editor. Arthritis and allied conditions. 10th ed. Philadelphia: Lea and Febiger; 1985:850-66.

15. Olivieri I, Barozzi L, Favaro L, Pierro A, de Matteis M, Borghi C, et al. Dactylitis in patients with seronegative spondylarthropathy. Assessment by ultrasonography and magnetic resonance imaging. Arthritis Rheum 1996;39:1524-8.

16. Kane D, Greaney T, Bresnihan B, Gibney R, FitzGerald O. Ultrasonography in the diagnosis and management of psoriatic dactylitis. J Rheumatol 1999;26:1746-51.

17. Wakefield RJ, Emery P, Veale D. Ultrasonography and psoriatic arthritis. J Rheumatol 2000;27:1564-5.

18. Olivieri I, Barozzi L, Pierro A, De Matteis M, Padula A, Pavlica P. Toe dactylitis in patients with spondyloarthropathy: assessment by magnetic resonance imaging. J Rheumatol 1997;24:926-30.

19. Olivieri I, Scarano E, Padula A, D’Angelo S, Salvarani C, Cantini F, et al. Fast spin echo-T2-weighted sequences with fat saturation in toe dactylitis of spondyloarthritis. Clin Rheumatol 2008;27:1141-5.

20. Healy PJ, Groves C, Chandramohan M, Helliwell PS. MRI changes in psoriatic dactylitis-extent of pathology, relationship to tenderness and correlation with clinical indices. Rheumatology 2008;47:92-5.

21. Fournié B, Margarit-Coll N, Champetier de Ribes TL, Zabraniecki L, Jouan A, Vincent V, et al. Extrasynovial ultrasound abnormalities in the psoriatic finger. Prospective comparative power-doppler study versus rheumatoid arthritis. Joint Bone Spine 2006;73:527-31.

22. Tinazzi I, McGonagle D, Zabotti A, Chessa D, Marchetta A, Macchioni P. Comprehensive evaluation of finger flexor tendon entheseal soft tissue and bone changes by ultrasound can differentiate psoriatic arthritis and rheumatoid arthritis. Clin Exp Rheumatol 2018;36:785-90.

23. Girolimetto N, Costa L, Mancarella L, Addimanda O, Bottiglieri P, Santelli F, et al. Symptomatic psoriatic dactylitis is associated with ultrasound determined extra-synovial inflammatory features and shorter disease duration. Clin Rheumatol 2019;38:903-11.

24. Helliwell PS, Firth J, Ibrahim GH, Melsom RD, Shah I, Turner DE. Development of an assessment tool for dactylitis in patients with psoriatic arthritis. J Rheumatol 2005;32:1745-50.
25. Möller I, Janta I, Backhaus M, Ohrndorf S, Bong DA, Martinoli C, et al. The 2017 EULAR standardised procedures for ultrasound imaging in rheumatology. Ann Rheum Dis 2017;76:1974-9.

26. Backhaus M, Burmester GR, Gerber T, Grassi W, Machold KP, Swen WA, et al. Guidelines for musculoskeletal ultrasound in rheumatology. Ann Rheum Dis 2001;60:641-9.

27. Naredo E, D’Agostino MA, Wakefield RJ, Möller I, Balint PV, Filippucci E, et al. Reliability of a consensus-based ultrasound score for tenosynovitis in rheumatoid arthritis. Ann Rheum Dis 2013;72:1328-34

28. Gutierrez M, Filippucci E, Salaffi F, Di Geso L, Grassi W. Differential diagnosis between rheumatoid arthritis and psoriatic arthritis: the value of ultrasound findings at metacarpophalangeal joints level. Ann Rheum Dis 2011;70:1111-4.

29. Wakefield RJ, O'Connor PJ, Conaghan PG, McGonagle D, Hensor EM, Gibbon WW, et al. Finger tendon disease in untreated early rheumatoid arthritis: a comparison of ultrasound and magnetic resonance imaging. Arthritis Rheum 2007;57:1158-64.

30. Terslev L, Naredo E, Iagnocco A, Balint PV, Wakefield RJ, Aegerter $\mathrm{P}$, et al. Defining enthesitis in spondyloarthritis by ultrasound: results of a Delphi process and of a reliability reading exercise. Arthritis Care Res 2014;66:741-8.

31. Filippou G, Di Sabatino V, Adinolfi A, Bertoldi I, Picerno V, Biasi $\mathrm{G}$, et al. No enthesis should be overlooked when psoriatic arthritis is suspected: enthesitis of the extensor digitorum tendons. J Rheumatol 2013;40:335.

32. Terslev L, Naredo E, Aegerter P, Wakefield RJ, Backhaus M, Balint $\mathrm{P}$, et al. Scoring ultrasound synovitis in rheumatoid arthritis: a EULAR-OMERACT ultrasound taskforce-Part 2: reliability and application to multiple joints of a standardised consensus-based scoring system. RMD Open 2017;3:e000427.

33. D'Agostino MA, Terslev L, Aegerter P, Backhaus M, Balint P, Bruyn GA, et al. Scoring ultrasound synovitis in rheumatoid arthritis: a EULAR-OMERACT ultrasound taskforce-Part 1: definition and development of a standardised, consensus-based scoring system. RMD Open 2017;3:e000428.

34. Tan AL, Fukuba E, Halliday NA, Tanner SF, Emery P, McGonagle D. High-resolution MRI assessment of dactylitis in psoriatic arthritis shows flexor tendon pulley and sheath-related enthesitis. Ann Rheum Dis 2015;74:185-9. 